\title{
INTERNATIONAL BUSINESS NEGOTIATION STRATEGIES BASED ON ASSESSMENT OF NEGOTIATING POWERS
}

\author{
Kęstutis Peleckis \\ Department of International Economics and Business Management, \\ Vilnius Gediminas Technical University, \\ Sauletekio al. 11, LT-10223 Vilnius, Lithuania \\ E-mail:k.peleckis@vgtu.lt
}

\begin{abstract}
The aim of the article is to make integrated analysis of current practice and theory in international business negotiations on creation of negotiation strategies and their implementation, to reveal opportunities for improvement of strategies creation and implementation according the needs to assess negotiating power reasonably of international business, to create theoretical model of development and implementation strategies of international business negotiation, based on evaluation of negotiating powers. The object of the article is international business negotiation strategies, their design and implementation processes, the needs and possibilities for their improvement, considering the assessment of the negotiating powers feasibility factors. The article seeks to identify the key elements of negotiating powers, determining the potential of negotiating, their adequate evaluation and configuration options, affecting the course and efficiency of international business negotiations.
\end{abstract}

Keywords: negotiation power, negotiation strategies, bargaining power, power assessment, negotation strategy preparation, international business negotiations.

JEL Classification: F51; M16.

\section{Introduction}

Now business needs to find new ways to ensure its growth and competitiveness in the international market. Business solutions, which today are used for development and implementation of international business negotiation strategies, are not universally suitable for the development of business in all situations in the current context of globalization and current challenges, which are described by increasing risk and uncertainty. In international business negotiations raise new challenges based on a common cultural and information space formation on a global scale, on new demands of information technology development progress in the field of international competition and the increasing pace of innovation processes. The development and implementation of unique and effective strategy in international business negotiations, setting the essential features and causal relations is important in order to make effective use of the potential of business negotiations - negotiation power. Solving scientific problem is necessary to ensure the use of such solutions would take into account the negotiating power of participants, would allow the implementation of business strategies and ensure that the development and implementation of it would be effective.
The object of the article is international business negotiation strategies, their design and implementation processes, the needs and possibilities for their improvement, considering the assessment of the negotiating powers feasibility factors. The article seeks to identify the key elements of the negotiating powers, determining the potential of negotiating, their adequate evaluation and configuration options, affecting the course and efficiency of international business negotiations.

The aim of the article is to make integrated analysis of current practice and theory in international business negotiations on creation of negotiation strategies and their implementation, to reveal opportunities for improvement of strategies creation and implementation according the needs to assess international business negotiating power reasonably, to create theoretical model of international business negotiation strategies development and implementation, based on evaluation of negotiating powers.

The problem analyzed in article - in management and business management theory there are no theoretical solutions for the assessment of negotiating power in international business negotiations. 


\section{Relevance and level of investigation}

Relevance of the article has both theoretical and practical aspects. Theoretical relevance is associated with searching of factors on international business negotiations strategy efficiency in scientific researches and creating the model for effective systemic and complex theoretical business negotiation strategy based on the assessment of the negotiating powers. Practical relevance is related to the recent changes in the business markets, by them determined challenges of business organizations, targeted recent developments, which occur by the increasing impact of electronic technology on business processes, negotiations, their effectiveness and, ultimately, for increasing the competitiveness of international businesses. Therefore, theoretical and practical relevance of article can be defined by the need to create model of business negotiation strategy, which could help for the participants and their competitors' to evaluate their negotiating power, effectively develop and use bargaining power to ensure creation of effective business negotiation strategy for the development and implementation international business and increasing its competitiveness.

In the scientific literature the theoretical aspect of the strategies as well as business negotiation strategies examined the following authors:

Herbst et al. (2008), Stokke (2011), Webb et al. (2011), Lemieux (2005), Resinas (2008), Miesing, Pavur (2008), Gunia et al. (2010), Andersen (2004), Ofir (2014), Litov et al. (2012), Rodica (2012), Williamson'as (2007), Smith (2003), Akramov (2011), Mintzberg et al. (2003), Johnson et al. (2008), Herman et al. (2011), Lincke (2003) and others. Analysis of scientific literature shows that there are conflicting views: some authors argue that the strategy must be unique (Litov et al. (2012), Rodica (2012), Williamson'as (2007), Smith (2003), Akramov (2011) and others), and another group of scientists argue that it can be of a general nature (Johnson et al. (2008), Herman et al. (2011), Lincke (2003), Rodica (2012), Stokke (2011), and others). Importance of negotiating powers for negotiation strategy emphasized a number of scientists: Keltner et al. (2008), Liu (2011), Hall et al. (2005), Guinote (2007), Van Kleef et al. (2006), Meehan, Wright (2012), Laing, Lian (2005), Blois (2005), Cox (2004), Hingley (2005), Pinnington, Scanlon (2009), Ireland (2004) and Blois (2005), Murtoaro, Kujala (2007) and others. These authors usually are researching negotiating powers of negotiators and opponents, but rarely examine the power and influence of other interested participants in negotiations (competitors, potential alternatives) on the negotiation strategy.

\section{Theoretical approaches to the business negotiation strategies. Adaptation of these approaches in accordance with modern international business development needs and challenges}

Negotiation strategy concept is multivariate. The lack of a common approach in scientific literature to this concept and description of its elements, there are not formed signs for identification and classification of negotiation strategy, missing of consistent terminology for description of business negotiations phenomena and its problems. This demonstrates the need to develop and adapt for contemporary needs relevant concepts and criteria. In the absence of a generally accepted definition of the term "negotiating strategy" due to differences in treatment of negotiation strategy factors importance in international business, arises a problem on assessment adequacy of e negotiating powers of business entities in international business negotiations. Therefore, in the article is appropriate to carry out an analysis of the business negotiation concepts and strategies in order to define adequately the business negotiations phenomena and problems. Considering "negotiation" definition in scientific literature is not found consensus on its content, but is often used other term as a synonym of negotiations - "bargaining". Usually negotiations cover the whole cycle: preparation, information exchange, the bargaining process, the outcome of the negotiations, analysis after negotiations. And bargaining is only the communication process between negotiating sides. Herbst et al. (2008) says that regardless whether or not negotiations taking part in the company or outside it, they reflect the interdependent decision-making processes in which can win two or more sides if they are in cooperation.

Negotiations are defined as an event where individuals cannot achieve the optimal solution without help of others (Stokke 2011). It can also be noted that negotiations are based on the communication between interests of two or more conflicting participants. Communication can take many different forms depending on the mode of communication. Negotiations usually take place face to face (Stokke 2011), but due to increasing speed of globalization and technological development there are new challenges, which are related to the global human resources, money, products and media dissemination. Negotiations - is a method 
(Herbst et al. 2011) that allows for two or more parties to reach agreement in order to communicate, modify or refrain from changing their relationship against each other, their relationships with others, or the relationship with the object of negotiations. It should be noted that these authors distinguish the following components of the negotiations concept: this is a process in which there are at least two negotiating parties and endeavor of goals. Thus, from the definitions given, it is possible to formulate a common definition of the concept of negotiations: negotiation is a process in which at least two negotiating parties pursue their goals.

The success of negotiations depends strongly on negotiators readiness, from strategy preparation, appropriate selection of tactics, negotiating behavior - negotiations style of a particular situation. However, the author, by analyzing scientific literature has determined that some scholars have different approaches to negotiations strategy formulation process. Stokke (2011) speaks about two basic strategies in negotiations: distributive and integrative. Distributive approach to negotiations is related on how participants have an interest to divide the different elements with each other, to get for them maximum benefits, while maintaining a strong focus on their own goals (Stokke 2011). Distributive negotiations approach is more focused on structural nature and process. This approach is based on the assumption that negotiations are a zero-sum transaction. In other words, the negotiator looks to negotiations like a race for limited and both sides desired benefits, which one would receive if another losses (Alfredson and Cungu 2008). Distributing strategies (Alfredson and Cungu 2008), otherwise known as a zero-sum, or win-lose strategies are based on a competitive negotiation point of view. These strategies in order to maximize the benefit of one side are leaving the other side with less winnings. As a result, if any participant increases value of his result, means reduction of another participant result. Therefore, for this type of negotiations participants must have to set the lower limit of the deal, which they would not change in any way in order to reach it (Stokke 2011). Integrative approach defines negotiation as a win-win potential. The integrated approach of negotiations is based on the assumption that the results of negotiations aim to provide a high level of satisfaction for all participants (Stokke 2011). This can be achieved by ensuring that no one of participants will suffer major losses, and the whole process of negotiations is devoted for this. It also states that participants must have a successful search for a solution that would lead towards posi- tive experience. There are several techniques of fundamental concept, which allows better understanding of this process (Alfredson and Cungu 2008). The first concept states that participants firstly have to create the greatest possible value to the other side of negotiations, and to themselves, and only then to require same from other side (Alfredson and Cungu 2008). Integrative approach of negotiations examines the internal interests of the participants - objective of the negotiations is the result, which would meet each participant's wishes as much as possible (Stokke 2011). However, in order to deal effectively with the challenges arising from integrative negotiations, the negotiator must carefully analyze situation of negotiations, develop a strategy and implement the tactics in compliance with the above provisions (Stokke 2011). Integrative approach uses objective criteria and aims to create conditions for their mutual benefit, promotes the exchange of information between the participants in order to deal with the problem effectively for negotiating sides. An integrated approach encourages problem-solving, cooperation, joint decision-making and common goals, integrative strategies encourage the participants to work together in order to create a win-win type of decisions. Decision process touches unknown interests also, generates opportunities, searching for common ground among participants. This approach of negotiations is derived from the investigations of international relations, political theory, labor disputes and social decision-making (Alfredson and Cungu 2008).

These authors are trying to classify negotiation strategies for all available situations. But each situation can be unique when there are different environment, politics, communication aspects, social and cultural factors and most importantly, when situation may change many times during the negotiation cycle. Furthermore, it would be illogical to use solely avoidance strategy both in negotiating about the price and terms for execution, quality, and so on. On prices subject it is available to cooperate, maturity issue should be avoided and negotiating about the quality should be adapted to the needs of other party. These roles should be performed by negotiating tactics and in formulating strategy should be seen only the most important aspects of strategic decisions. Therefore, the author proposes to classify strategic decisions and tactics rather than strategy, which basically has to be original and dedicated for unique situation. Due to the lack of uniform definitions of the negotiations in a special literature the same terminology is treated differently. Various authors of the same concept call the negotiating strategy as tactics, style, per- 
sonality type, negotiation type, model, negotiator priority and so on (for example, the negotiations focus on the relationship or to score). The following is an analysis of the negotiations tactics and negotiation style concepts and types used in the scientific literature. In the scientific literature can be found a few hundreds of negotiating tactics even. Let us consider some of them, which usually are mentioned by authors in special literature. ESCAP (2004) makes the following tactics: persuasion, misleading, mutual exchange, deadlock avoidance, avoidance tactics, attraction attention of others, ultimatums management, management of dirty instruments. Lincke (2003) points out the following negotiating tactics: short-term approach, perseverance and belonging, short-term actions. Herbst et al. (2011) refers to these negotiating tactics: pressure, fairness, sharing, coalition integration, rational persuasion, inspirational appeal, advice, personal appeal. Herbst et al. (2011) notes that there is little research on negotiation tactics, which indicates the lack any theoretical base.

Negotiation styles can be selected or determined by the personal qualities that are inherent and predetermined on social culture. Lincke (2003) argues that negotiating styles can be part of the strategy and tactics, but colleague of negotiations may attribute it to your personality. Negotiation strategy is described as the relationship between personality and negotiation style, which can be explained by the metaphor of iceberg; strategy is visible at the top of iceberg as it negotiator may choose consciously, and the negotiator's style is the negotiator's personality for which he / she has almost no influence. The style is below sea level, this means that it is not visible but has an impact on visible top of iceberg (strategy). Lincke (2003) presented the following negotiating styles: avoidance, investigation. The author classifies the negotiation style as well as the aforementioned authors classified the general negotiation strategies and tactics. Negotiation style depends on the negotiator's interpersonal behavior, and is often influenced by the chosen strategy respectively. Authors Ofir (2014) and Herman et al. (2011) describe the negotiating styles of international business negotiations:

1. The competing style. That is style which has features of noncooperation and categoricalness The participants seek their goals at the expense of another side of negotiations. They use poweroriented model, where are using that they need in order to win.

2. The cooperative style. That is style which has both categoricalness, as well as collaboration features, unlike the avoidance style. Collaborated styles include the desire to cooperate with the other participant, finding solutions that fully satisfy objectives of both negotiations sides. This means that both sides of negotiations go deep into negotiations questions and are identifying the main problems, as well as finding the key issues of alternatives that can satisfy all objectives of negotiations sides.

3. Adaptation style. This style has cooperation and non-categoricalness features, unlike competing styles. The participants ignore its own problems, in order to meet interests of other negotiation side. It is altruistic style.

4. Avoidance style. This style has noncategoricalness and non-cooperation properties. The participants do not seek to solve their problems immediately, does not seek conflict. Avoidance gets postponement of problem, waiting for a better moment or to avoid a dangerous situation.

5. Compromise style. This style is an intermediate position between categoricalness and cooperation. Its purpose - to find appropriate solutions to the problem, which would be mutually acceptable and partially will meet the expectations of negotiating sides. This style has characteristics of both competition and adaptation styles.

From the analysis of scientific literature it is possible to formulate these definitions of negotiations:

The negotiations - a process in which at least two negotiating sides aims to achieve their own goals.

Negotiation strategy - a unique process that occurs over time, during which are used all the negotiating powers of business entity (entities or business units) to achieve the negotiating objectives, taking into account the context of negotiations and environmental factors.

Negotiation strategy solution - one of possible strategies and significant steps planned to carry out in the implementation of the negotiating strategy.

Negotiating tactic - a set of specific measures and actions, characterized by a certain common aspect necessary for implementation of negotiating strategy.

Based on these concepts we will explore business negotiating phenomena and problems as well identification and classification signs systems of negotiating strategy. Knowing that negotiating power is the basis for negotiating strategy it is the need to know better the nature of negotiating power: sources, elements and their interrelations. In preparation of strategy of international business negotiations it is important to understand and evaluate the most important negotiating powers leading 
to it. It is also appropriate to examine in greater detail the concept of power and its typology.

\section{Review of research on negotiating powers presented in scientific literature}

Power definitions are derived from social exchange theory: the power can be considered under at least two sides of interface. The examination of interacting negotiators having equal powers is dealing with the question: how perception of interdependence leads to a uniform mutual influence. Rubin and Brown presented a description of negotiations is essentially formed by the mutual influence and social exchange approach which includes negotiating parties in the process of negotiation interactions. This helps to understand the importance of negotiating power (Wolfe, McGinn 2005). According to social exchange theory, the negotiator, who is less dependent on the opponent than the opponent from the negotiator, has more power in negotiations to achieve for himself (his side of negotiations) a more favorable result. The power between negotiators becomes more balanced when negotiators become more dependent from each other, seeking to achieve mutually acceptable results.

Some researchers (Kim et al. 2005) break down the negotiating power into three components: potential power, perceived power, realized power. The potential power is defined as negotiators potential benefit from a future agreement. Perceived power is defined as a negotiators evaluation by providing how opponent's potential power will affect their relationship. Realized power indicates the extent to which one side of negotiations will get its benefit from the interaction with the other side of negotiations. When assessing the power of negotiator, the other negotiator is taken as the basis for comparison. Account is taken with whom negotiator can interact using his power in negotiation process. Past experience and future expectations act perception of relations and their conditions. Evaluation of opponent's power, knowledge of the differences and similarities of his opponent allow negotiators more easily to control their bargaining interaction and thus they become better prepared to forecast the behavior of opponent and how they can properly respond to this (Wolfe, McGinn 2005).

Many negotiators believe that power is important because it provides an advantage over the other negotiator. Negotiators who have this advantage mainly seek to use it trying to achieve a better result or preferred solution. Aspiration on enhancement of power in negotiations usually follows from two approaches (Lewicki et al. 2015):
1. The negotiator believes that he has less power than the other side. In this situation negotiator believes that the other side has an advantage which can or will be used, so he will seek to offset or compensate it.

2. The negotiator believes that he needs more power than other side has, in order to increase the desired outcomes. In this context, the negotiator believes that the added capacity will be important in order to strengthen his advantage in future negotiations.

These two approaches cover important issues of negotiations tactics and motives (Lewicki et al. 2015). Tactics can be formed so that the negotiator will increase his power or reduce the power of the other side and will create a balance of powers (relatively equal power) or differences of powers (one's power will be higher than the others). Therefore occurs question: why does negotiator use tactics of one or another form. There are two reasons for this. The first and probably most likely that the negotiators use the tactics to create power differences and seek for advantage against another participant's power steps. Such tactics encourage one side to dominate in relations using the dominant or competitive strategy and focusing on the outcome of negotiations (Lewicki et al. 2015). Another reason is rare, but no less important: the negotiator uses appropriate tactics in order to achieve a balance of powers. Using such tactics can be decreased other negotiating side dominance in relationship.

This encourages negotiators to seek for compromise, cooperating, integrative agreement. In order to discover the nature of power and its relation with business negotiations and to establish the negotiating powers it is appropriate to extend the investigation of powers definitions. Next we will look at the power concepts and their development. There are different approaches to power due the complexity of the phenomenon. Many sources of bargaining power are treated as very important element of negotiations. Cox (2004) and Hingley (2005) argue that power is the basis and essence of negotiations. Power is as old as the negotiations, but research on this topic has been a very long time not enforced. Power concept is ancient and universal - any social theory can boast of it (Hingley 2005; Ireland 2004).

Konig et al. (2011) sees the bargaining power as a potential impact of one side to results of other side and Benton and Maloni (2005) see the power as ability to influence the behavior of other side to the desired direction. Power is a very broad concept, which is described in very different contexts 
and in different ways. One possible view describes power - making an impact on other (Konig et al. 2011). For example, Keltner, Gruenfeld, Anderson (2003) describe the power as the relative capacity of the individual to change the others person's positions by giving or capturing resources, or imposing the penalties. It arises from the fact that the actions and decisions have an impact on others. Power is defined as the potential impact, which is substantial in business, management (Blois 2005; Cox 2004; Hingley 2005; Meehan, Wright 2012; Pinnington, Scanlon 2009; Svensson 2002; Meehan, Wright 2012). Although power is indirectly included in the business interactions (Meehan, Wright 2012), mutual impacts of buyers and sellers, impact objects naturally vary (Meehan, Wright 2012). Analysis of partnership relations have shown that this is a powerful source in developing sustainable competitive advantages (Meehan, Wright, 2012; Chen et al. 2004; Wong, Tjosvold, Zhang 2005). Power is some potential to influence, which is expressed in all customer and seller relationships. Power is the potential to achieve the desired results in social relations, as the result of asymmetrical dependence or valued resource control (Meehan, Wright 2012).

In future will be used such definition of negotiating power - entirety of entity capabilities and its activities typical factors that are key for negotiating targets and their implementation. This definition would be appropriate to refer in business negotiations. No less important is the evaluation of negotiating powers, because strategic negotiating solutions without it would be inadequate. Therefore, it is appropriate to define the negotiating power assessment as the identification process of entities participating in negotiations, goals, their reasonableness, implementing conditions and capabilities. Next we will look in more detail to negotiating powers and typology of basic principles for the use of power. This will contribute better to reveal power sources and power relationship with outcomes of negotiations. The following will review typology of power and the main developments in this field, dealing with social power. The results of research may have a significant impact on better perception of negotiating powers and their characterization. Investigations in this field have developed and improved these researchers Liu 2011; Blois in 2005; Cox, 2004; Hingley 2005; Meehan, Wright 2012; Pinnington, Scanlon 2009, Svensson 2002; Meehan, Wright 2012. In their works social influence is described as the human persuasion, change of attitude, in order to make impact, attempt to influence the other side, a per- son or group of persons. Social power is defined as the potential for such influence. Here, the power is seen as an opportunity to benefit in future from external impact of social status (Liu 2011) in order to access the desired resources. Liu (2011) says that the extent of the power or the power of differentiation depends on the relations between the participants or their perception. Typology consists of six power elements that influencing person may use to change another person's attitude or behavior (Liu 2011):

1. The power of violence occurs when a person realizes that the other side may punish him. Power derived from violence is used for the one, who has the opportunities to punish others.

2. The power of award is based on the understanding that the other side is capable to make reward. Power, arising from the reward options can be used by any person who has the resources to repay you.

3. The legal power is based on the opportunity to influence the other side, making the impact of legislative measures.

4. The expert power arises from the perception that the other side (expert) has the relevant knowledge and experience.

5. The power of delegation may act through someone's favorable attitude to a person in their mutual relations, to whom is delegated the appropriate power.

6. The information power is the potential to influence the other side on the relevance of the information provided. Information power occurs after presentation of a logical explanation or new information which induces changes in the relevant field.

A clear understanding of power and its treatment - a key strategy requirement, but the power must objectively exist and have possibilities to make influence. The negotiator must know his power, and the opponent has to believe in them and adopt them. The core of power is its possession and perception of that. The available power of one side of negotiations and perception about this of other side of negotiations, access to resources and resources value determine force of power. After analyzing the results of research about nature and power of perception, it can be said that importance of power assessment is an essential part of negotiations.

\section{The international business negotiations strat- egy based on evaluation of negotiating powers and theoretical its development model}

Following is (Fig. 1) the negotiations strategy model based on negotiating power assessments. In 
this model are provided factors, which are influencing the negotiating powers. The author believes that negotiation strategies must be developed on the basis of evaluation negotiating power, negotiation potential, as it is exceptionally important aspect in order to adopt decisions the negotiations of strategy development and implementation, giving adequate and maximal winnings.

Evaluation of the negotiating power. The model shows that in assessing negotiators (negotiations team) negotiating powers, must be taken into account the available alternatives, possibilities of existing competitors and negotiating powers of other negotiator-opponent (negotiations team opponents). In the literature, importance of alternatives (BATNA, etc.) in negotiations is emphasized as essential, because in case of absence available alternatives, negotiators mostly have to agree with the opponent's conditions. Having alternatives, the opponent cannot dictate his conditions and has to provide more favorable proposals. Knowing that the other side has negotiations alternatives just forces to negotiate. In order to determine the opponent's negotiating powers is very important the knowledge and evaluation of competitors. Just knowing them is possible to seek and obtain the maximum winnings, otherwise the dividend could be much worse. In international business negotiations self and opponents knowledge is important both for the harmonization of multiculturalism aspects, communication setting conditions and knowledge of negotiation context.

Pre strategic steps. Negotiation strategy development process requires pre strategic steps: the selection of negotiations orientation and negotiation type. Negotiation orientation can be seen as orientated to the results or to relationship. Orientation to the results shows that there are critical onetime winnings, and do not see non into the future of relations nor to the possible deals - it is a shortterm approach. Orientation to the relationship, by contrast, shows a long-term attitude to further deals. Maybe they alone will not be very profitable, but in the long run, they can pay off and provide a lot greater cumulative winning than orientation to a single result - to a single deal. There may be optional such types of negotiations: competition, avoidance, cooperation, adaptation or compromise. These solutions define further activities of negotiating strategy development and their content.
Steps of strategy development. Development of negotiation strategy, based on assessment of possibilities and influence of negotiator, opponents alternatives, competitors. It is essential the evaluation of these entities and the use of generated information for negotiations strategy development. Negotiation development strategy steps are: the formation of power, selection of tactics, selection of negotiating steps. Power can be formed with these negotiating power elements: knowledge, conditions of communication, time management, emotional management, expectation management, ethics and etiquette. Tactics can be as follows: pressure, coalition, consultation, delays, bluffing, ironing, withdrawal, misrepresentation, ultimatum, persuasion, distortion and so on. With the help of negotiating steps goes planning of developed strategy and on this bases are selected tactics for influencing negotiations opponent (negotiations teamopponent), submitting specific proposals, offering discounts and in order to get from the opponent asmore significant discount for yourself in exchange for us less important discount.

Negotiation phases and situational power. The negotiation includes the following phases: preparation, information exchange, bargaining process, outcome of negotiations and its analysis. Negotiation strategy is implemented on the basis of selected negotiating tactics by negotiating steps in negotiating process phase, supplying concrete proposals, thus increasing their situational negotiating power. Situational power varies over time depending on the negotiator and his opponents negotiating steps and their results. Research results showed that the basis of negotiating strategy - negotiating power, so in preparing negotiating strategy must be focus on the assessment of negotiation participants, their negotiating powers. In the preparation of the international business negotiation strategy is essential to understand and evaluate the key it determining negotiating powers.

Evaluation of negotiation power and forming is particularly relevant in international business negotiations, where it is necessary to harmonize the processes of interaction between participants of different cultures, considering the context of the negotiations, cultural differences, conflict prevention.

Evaluation of these internationalization aspects is relevant, in order better exploit the potential of negotiating powers in international business negotiations. 


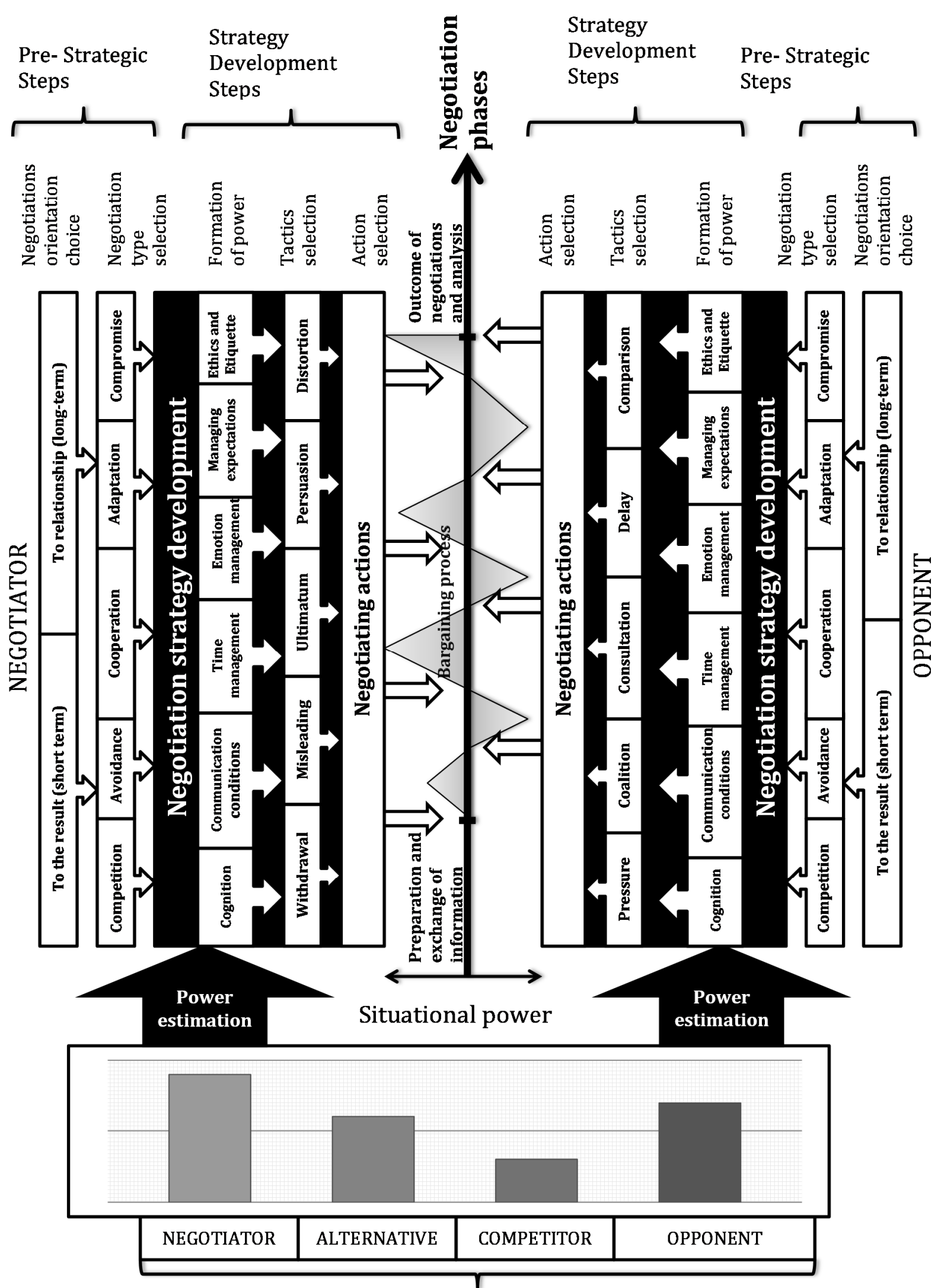

THE NEGOTIATING POWER OF NEGOTIATIONS STAKEHOLDERS

Fig. 1. Theoretical model of international business negotiation strategy development based on assessments of negotiation power 


\section{Conclusions}

1. In theory of management as well as business management are not theoretical solutions for the assessment of bargaining power in international business negotiations. International business negotiation strategies are developed without taking into account assessments of bargaining power, simply cannot be of high quality, comprehensive, integrated. The performed literature review indicates that there are no constructive proposals of negotiating power evaluations in scientific literature. Complex analysis of unfolding in international business negotiating theory and practice of negotiating strategies development and implementation show that there is a need to develop a theoretical model for the international business negotiating strategies based of negotiating power evaluations.

2. The analysis of the of negotiation strategy concepts showed that there is no negotiating strategy definitions, which are treated equally. The analysis of the results of research on the nature of power as the phenomenon and perception, it can be said that the importance of power in negotiations is essential. Research results showed that the negotiating power is the essence of negotiating strategy, so in preparing negotiating strategy it is necessary to concentrate on assessment of negotiating power of negotiating sides.

3. It can be named a few the most important power elements of negotiations: preparation, communication conditions, ethics, emotion management, time management, management of expectations. These elements of negotiation power are the most important factors for success of negotiating strategy and in preparing of it must rely on them. Analyzing negotiations strategies and its implementation is noted that powers of participants in negotiations may vary from changing situation, even moving from one point of the negotiations to another, after one or the other negotiating step or action. Thus, the ratio of negotiating power may change with the changing situation in negotiations.

4. After analysis of power definition it is proposed to use such negotiating power definition - it is a whole of entity capabilities and for its activity typical conditions determining arising od negotiations targets and their implementation. Therefore, the assessment of negotiating power should be seen as identification of negotiation goals, their reasonableness, implementing conditions and capabilities of entities participating in process of negotiations.

5. In the article is given the negotiations strategy model based on assessments of negotiating power. In this model are provided factors, which are influencing the negotiating powers. The author believes that negotiations strategy has to be developed on the basis of assessments of negotiating power, negotiation potential, as it is exceptionally important aspect in order to adopt the negotiations strategy and decisions of implementation, giving adequate and maximum winnings.

\section{References}

Akramov, T. 2011. Marketing strategy: concepts and implication. Marketing strategy: concepts and implication. Vol. 4. Central Bohemia University: 52-55. ISSN 18045839.

Alfredson, T.; Cungu, A. 2008. Negotiation Theory and Practice: A Review of the Literature: Section 3. EASYPol. 1-32 p.

Andersen, T. J. 2004. Integrating the strategy formation process: an international perspective, European Management Journal 22(3): 263-272. ISSN 02632373. http://dx.doi.org/10.1016/j.emj.2004.04.008

Benton, W. C.; Maloni, M. 2005. The influence of power driven buyer/seller relationships on supply chain satisfaction, Journal of Operations Management 23(1): 1-22. http://dx.doi.org/10.1016/j.jom.2004.09.002

Blois, K. 2005. Self-interest and not benign power-A comment on Hingley's "Power to all our Friends", Industrial Marketing Management 34(8): 859-862. http://dx.doi.org/10.1016/j.indmarman.2005.02.002

Chen, I. J.; Paulraj, A.; Lado, A. 2004. Strategic purchasing, supply management and firm performance, Journal of Operations Management 225(5): 505 523. http://dx.doi.org/10.1016/j.jom.2004.06.002

Cox, A. 2004. Business relationship alignment: On the commensurability of value capture and mutality in buyer and supplier exchange, Supply Chain Management: An International Journal 9(5): 410-420. http://dx.doi.org/10.1108/13598540410560793

ESCAP - Economic and social commission for Asia and the Pacific. 2004. Least developed countries in trade negotiations: policy process and information needs. Bangkok. 24 p.

Guinote, A. 2007. Power and goal pursuit, Personality and Social Psychology Bulletin 308(8): 10761087.

http://dx.doi.org/10.1177/0146167207301011

Gunia, B.; Thompson, L.; Wang, J. 2010. Negotiation, Annual Review Psychology 61: 491-515. http://dx.doi.org/10.1146/annurev.psych.093008.1 00458

Hall, J. A.; Coats, E. J.; LeBeau, L. S. 2005. Nonverbal behavior and the vertical dimension of social relations: a meta-analysis, Psychological Bulletin 131(6): 898-924. http://dx.doi.org/10.1037/0033-2909.131.6.898 
Herbst, U.; Schwarz, S.; Voeth, M. 2008. The management of intra- versus inter-organizational negotiations: An empirical comparison, in Proceedings of the 1st French - German - Swiss Workshop on B2B Marketing. Lausanne, Switzerland.15 p.

Herbst, U.; Voeth M.; Meister C. 2011. What do we know about buyer-seller negotiations in marketing research? A status quo anglysis. Industrial marketing management: the international journal for industrial and high-tech firms. New York: Elsevier. ISSN 0019-8501, ZDB-ID 1201244.Vol. 40.2011, 6, p. 967-979.

Herman, G. N.; Carry, J. M.; Kennedy, J. E. 2011. Legal counseling and negotiationg: a practical approach. Lexisnexis. 572 p. ISBN-13: 978-1422422625.

Hingley, M. K. 2005. Power inbalanced relationships: cases from UK fresh food supply, International Journal of Retail \& Distribution Management 33(8): 551-569.

http://dx.doi.org/10.1108/09590550510608368

Ireland, P. 2004. Managing appropriately in construction power regimes: Understanding the impact of regularity in the project environment, Supply Chain Management: An International Journal 9(5): 372-382. http://dx.doi.org/10.1108/13598540410560757

Johnson, G.; Scholes, K.; Whittington, R. 2008. Exploring corporate strategy: text and cases. Pearson Education Limited.

Keltner, D.; Van Kleef, A. G.; Chen, S.; Kraus, M. W. 2008. A reciprocal influence model of social power: emerging principles and lines of inquiry, Advances in Experimental Social Psychology 40: 151-192. http://dx.doi.org/10.1016/s0065-2601(07)00003-2

Keltner, D.; Gruenfeld, D. H.; Anderson, C. 2003. Power, approach, and inhibition, Psychology 110(2): 265-284.

Kim, H. P.; Pinkley, R. L.; Frafale, A. R. 2005. Power dynamics in negotiation, Academy of Management Review 30(4): 799-822. http://dx.doi.org/10.5465/AMR.2005.18378879

Koning, L.; Steinel, W.; van Beest, I.; van Dijk, E. 2011. Power and deception in ultimatum bargaining, Organizational Behavior and Human Decision Processes 115(1): 35-42.

http://dx.doi.org/10.1016/j.obhdp.2011.01.007

Laing, A. W.; Lian, P. C. S. 2005. Inter-organisational relationships in professional services: Towards a typology of service relationships, Journal of Services Marketing 192: 114-128.

http://dx.doi.org/10.1108/08876040510591420

Lemieux, J. M. 2005. A dynamic model of asymmetric price negotiation: Dissertation. The University of Texas at Austin. 124 p.

Lewicki, R. J.; Saunders, D. M.; Barry, B. 2015. Negotiation. $7^{\text {th }}$ ed. New York: McGraw Hill.
Lincke, A. M. T. 2003. Electronic business negotiation: some experimental studies on the interaction between medium, innovation context and culture: Dissertation. Universiteit van Tilburg UvT. 275 p.

Litov, L. P.; Moreton, P.; Zenger, T. R. 2012. Corporate strategy, analyst coverage, and the uniqueness paradox, Management Science 58(10): 1797-1815. http://dx.doi.org/10.1287/mnsc. 1120.1530

Liu, Y. 2011. Power perceptions and negotiations in a cross-national email writing activity, Journal of Second Language Writing 20(4): 257-270. http://dx.doi.org/10.1016/j.jslw.2011.06.001.

Meehan, J.; Wright, G. H. 2012. The origins of power in buyer-seller relationships, Industrial Marketing Management 41(4): 669-679.

http://dx.doi.org/10.1016/j.indmarman.2011.09.015

Miesing, P.; Pavur, E. 2008. Exercise: Stakeholder negotiations, Journal of Strategic Management Education 4(1): 187-210.

Mintzberg, H.; Lampel, J.; Quinn, J.B.; Ghoshal, S. 2003. The strategy process: concepts, contexts, cases. Upper Saddle River, NJ: Prentice-Hall.

Murtoaro, J.; Kujala, J. 2007 Project negotiation analysis, International Journal of Project Management 25(7): 722-733. ISSN 0263-7863. http://dx.doi.org/10.1016/j.ijproman.2007.03.002.

Ofir, M. 2014. The negotiation style: a comparative study between the stated and in- practice negotiation style, Procedia - Social and Behavioral Sciences 124: 200-209. ISSN 1877-0428.

Pinnington, B. D.; Scanlon, T. J. 2009. Antecedents of collective-value within business-to-business relationships, European Journal of Marketing 431/2: 31-45. http://dx.doi.org/10.1108/03090560910923229

Resinas, M. 2008. Automating the negotiation of agreements. A framework for developing automated negotiation systems: Doctoral dissertation. Universidad de Sevilla, Spain. 269 p.

Rodica, M. 2012. The balanced scorecard in a strategyfocused organization. The Bucharest Academy of Economic Studies, Romania. 10 p.

Smith, B. D. 2003. The effectiveness of marketing strategy making processes in medical market. Cranfield School of Management. Cranfield, United Kingdom. 278 p.

Stokke, R. A. 2011. An investigation of culture and creativity on negotiation: Doctoral dissertation. Queensland University of Technology. Queensland, Australia. $157 \mathrm{p}$.

Svensson, G. 2002. The measurement and evaluation of mutual dependence in specific dyadic business relationships. The Journal of Business and Industrial Marketing, 171: 56-74.

Van Kleef, G. A.; De Dreu, C. K. W.; Pietroni, D.; Manstead, A. S. R. 2006. Power and emotion in negotiation: Power moderates the interpersonal effects of anger and happiness on concession ma- 
king, European Journal of Social Psychology 36(4): 557-581. http://dx.doi.org/10.1002/ejsp.320

Webb, J.; Maughan, C.; Maughan, M.; Boon, A.; KeppelPalmer, M. 2011. Lawyers' skills 2011-2012. Legal Practice Course Guide. Oxford University Press. 264 p. ISBN-10: 0199609438.

Williamson, B. 2007. The relationship between IT, ITbusiness strategic alignment, and IT capability, International Journal of Managing Information Technology IJMIT 21: 16-31.
Wolfe, R. J.; McGinn, K. L. 2005. Perceived relative power and its influence on negotiations, Group Decision and Negotiation 14(1): 3-20. http://dx.doi.org/10.1007/s10726-005-3873-8

Wong, A.; Tjosvold, D.; Zhang, P. 2005. Developing relationships in strategic alliances: Commitment to quality and cooperative interdependence, Industrial Marketing Management 34(7): 722-731. http://dx.doi.org/10.1016/j.indmarman.2004.12.007 